UJBM, Vol. 6, No. 2, July - December 2007, pp 25-37

ISSN 0975-3311 | https://doi.org/10.12725/ujbm.11.3

\title{
THE ROLE OF MARKETING RESEARCH FOR ENTREPRENEURSHIP
}

\author{
Jyotirmoy Ghosh* and G. Anjaneyaswamy**
}

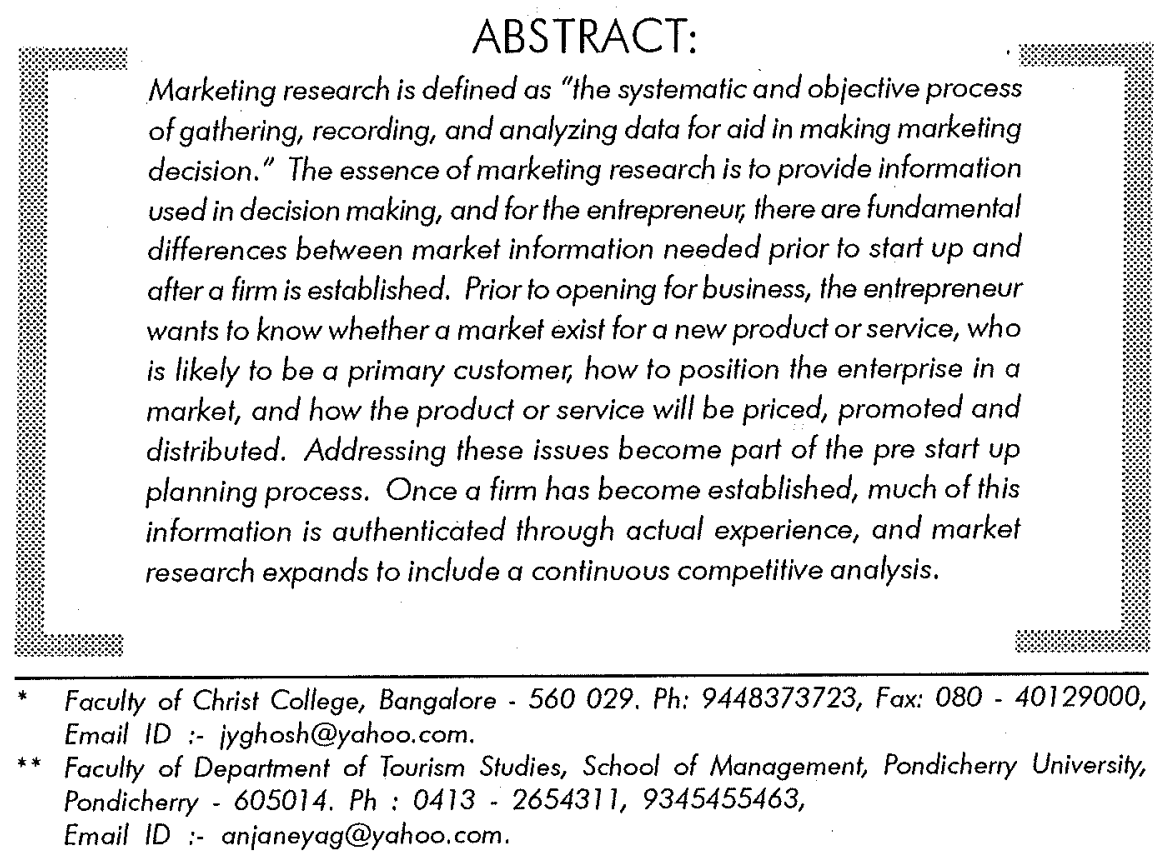


An effort has been made to demonstrate the above mentioned characteristics of marketing research undertaken by the entrepreneurs. The first half of the article portrays an effective framework of the methodology for marketing research. Entrepreneurial marketing research differs from its normal counterpart. These exclusive features are expressed and discussed in details. In the second part of the article, an effort has been made to narrate the nature of marketing research that can be ideally applied to all the different stages of successful venture life cycle.

The functioning of all the different stage of the life cycle are discussed with the corresponding markeling research techniques that can be ideally applied, being expressed.

\section{The Role of Marketing Research for Entrepreneurship}

Entrepreneurship is more than the mere creation of business. Although that is certainly a fact, it's not the complete picture. The characteristics of seeking opportunities, taking risks beyond security, and having the tenacity to push an idea through to reality combine into a special perspective that permeates entrepreneurs. Entrepreneurship is the symbol of business tenacity and achievement. Entrepreneurs were the pioneers of today's business successes. Their sense of opportunity, their drive to innovate, and their capacity for accomplishment have become the standard by which free enterprise in now measured. This standard has taken hold throughout the entire world. Entrepreneurs will continue to be critical contributors to economic growth through their leadership, management, innovation, research and development effectiveness, job creation, competitiveness, productivity and formation of new industry.

Satisfying customers is the fundamental objective of successful marketing in every organization. Achieving this objective involves far more than simply providing good service, and as we shall agree, success often rests with effective market planning. A market is a group of consumers (potential customers) who have purchasing power and unsatisfied needs. A new venture will survive only if a market exists for its product or service. This is so obvious that it would seem every entrepreneur would prepare thoroughly the market analysis needed for establishing a target market. However, many entrepreneurs know very title about their market, and some even attempt to launch new ventures without identifying any market. 
Thus for all practical purpose, entrepreneurs must do a great deal of serious market research to understand who their customers are and how best to serve them. Research activities should take place before opening the new venture, and they should continue throughout the venture's existence.

\section{Market Research for the Entrepreneur}

Market research begins with investigating the objectives or purpose. This is often the most difficult step since many entrepreneurs lack knowledge or experience in marketing and often don't even know what they want to accomplish from a research study.

\section{Defining the Purpose or Objectives}

The entrepreneur should first enlist all the information that will be needed to prepare the marketing plan. The entrepreneur may think there is a demand for his product, but is not sure who his customers will be or even if the product will be acceptable in its present form. Thus it will be logical for him to ask a group of potential customers and also decide on the demographic and attitude details of them. This operation is usually done by market research, and will help the entrepreneur be more certain about the success of the product, as well as have complete knowledge about the customers their gender, income level, age group, life style, taste fashion and so on.

The normal objectives of the entrepreneur would be:-

a) What price the customers are willing to pay.

b) Preference of selecting the product against that of the competitors.

c) What attributes of the product are preferred and also the attributes that are not preferred.

d) Where potential customers would prefer to purchase the product or service.

e) Where and how they will get full details of the product, its usage, its unique factors, its value for money, and so forth. 
According to marketing principles a) deals with price, b) and deals with product, c) deals with place or channel of distribution and d) deals with promotion which
includes advertising.

\section{Gathering Secondary Data}

The second step for the entrepreneur is to gather information from data that already exist. Existing data sources are known as secondary data. These are found in newspapers, trade magazines, library books, government agencies, and universities. A search in a library will often reveal published information on the industry, competitors' trends in consumer tastes and preferences, innovations in the market, and even specific information about strategies now being employed by competitors already in the market. The internet can also provide extensive information on competitors, the industry, and even provide insightful primary information directly from potential consumers who respond to chat groups.

Experts recommend that the entrepreneur spend time in a local business library scanning on-line catalogs and reference sources to locate articles that have been written about comperitors or the industry. These articles, although considered as secondary data, should be scanned to identify the names of individuals who were interviewed, referenced, or even mentioned in the article. These individuals can then represent sources to be contacted directly and thus later can act as primary data source. If their affiliation, telephone number, or address is not given in the article, then the entrepreneur should contact the author(s) of the article to see if they have these affiliations or could even provide some of their personal insight to some of the important market issues. The entrepreneur should ideally exhaust all possible secondary data sources, observation, and networking before starting the more costly primary data research.

\section{Gathering Primary Data}

The third step the entrepreneur should follow is to gather information from primary sources. The traditional data collection procedures from primary sources are by using observation, networking, interviewing, focus groups, or experimentation and the usage of a data collection instrument, such as a questionnaire.

\section{Observation}

Observational methods avoid contact with respondents, whereas questioning methods involve respondents in varying degrees. Observation is probably the 
oldest form of research in existence. Observational methods can be used very economically. Further more, they avoid a potential that can result from a respondent's awareness of his or her participation under questioning methods. A major disadvantage of observational methods, however is that they are limited to descriptive studies, which are mainly qualitative in nature.

\section{Networking}

Networking is an informal method to gather primary data from experts in the field, can also be valuable low - cost method to learn about the market place. Studies performed by experts show that the most successful ventures (based on development and profitability) where focused on information about competitors, the customer, and the industry, using networking, trade associations, and recent publications, less successful ventures were more focused on gathering information on general economic and demographic trends and hence had less knowledge about the happenings in their specific target market.

\section{Surveys}

Surveys include contact with respondents by mail, telephone, and personal interviews. Mail surveys are often used when respondents are widely dispersed; however, these are characterized by low response rates. Telephone surveys and personal interview surveys involve verbal communication with respondents and provide higher response rates. All these methods have their advantages and disadvantages and the entrepreneur should evaluate and choose what is most appropriate to him.

\section{Questionnaire}

The questionnaire is the main data collection instrument, used by the entrepreneur. Questions should be specifically designed to fulfill one or more of the objectives the entrepreneur established earlier. Questions should be clear, concise, unbiased and easy to answer.

\section{Focus Groups}

An effective and informal method for gathering in - depth information is the focus group method. A focus group is a sample of 10 to 12 potential customers who are invited to participate in a discussion relating to the entrepreneur's research objectives. The focus group discusses issues in an informal, open format, enabling the entrepreneur to ascertain certain information. 


\section{Experimentation}

Experimentation is a form of research that concentrates on investigating causeand-effect relationships. The target is to establish the effect, an experimental variable has on a dependent variable. For example, what will be the effect of price change of a product on the total sales? Here the price is the experimental variable, and sales volume is the dependent variable. Measuring the relationship between two variables may be a simple task. It becomes rather difficult when the variables are more.

\section{Analyzing and Interpreting the Results}

The fourth and final step is to analyze, interpret and report the results. After the necessary data have been accumulated, they should be developed into usable information. Large quantities of data are merely facts. To be useful, they must be organized and molded into meaningful information. Depending on the size of the sample, the entrepreneur can hand tabulate the results or enter them on a computer. In either case the entrepreneur evaluates and interprets in response to the research objectives that were specified in the first step of the research process.

The style of marketing research for entrepreneurs will vary considerably from that of normal market research. The facts to be investigated will be different as the ventures have different objectives. Thus it is worth analyzing the nature of questions that are ideally found in an entrepreneur's research questionnaire. The following can act as good guideline for the entrepreneur.

\section{Entrepreneur's Marketing Research Questions}

The need for marketing research before and during a venture will depend on the type of venture. However, typical research questions might include the following, which are divided by subject.

\section{Sales}

1. Do you know all about; you need to know about your competitor's sales performance by type of product and territory?

2. Do you know which accounts are profitable and how to recognize a potentially profitable one? 
3. Are your sales power deployed where it can do the most good, maximizing your investment in selling costs?

\section{Distribution}

1. If you are considering introducing a new product or line of products, do you know all you should about distributors and dealers attitude towards it?

2. Are your distributors and dealer's sales people saying the right things about your products or services?

3. Has your distribution pattern changed along with the geographic shifts of your markets?

\section{Markets}

1. Do you know all that would be useful about the differences in buying habits and tastes by territory and kind of product?

2. Do you have as much information as you need on brand or manufacture loyalty and repeat purchasing in your product category?

3. Can you now plot, from period to period, your market share of sales by products?

\section{Advertising}

1. Is your advertising reaching the right people?

2. Do you know how effective your advertising is in comparison to that of your competitors?

3. Is your budget allocated appropriately for greater profit according to products, territories, and market potentials?

\section{Products}

1. Do you have a reliable quantitative method for testing the market acceptability of new products and product changes?

2. Do you have a reliable method for testing the effect on sales of new or changed packaging? 
3. Do you know whether adding higher or lower quality levels would make new profitable markets for your products?

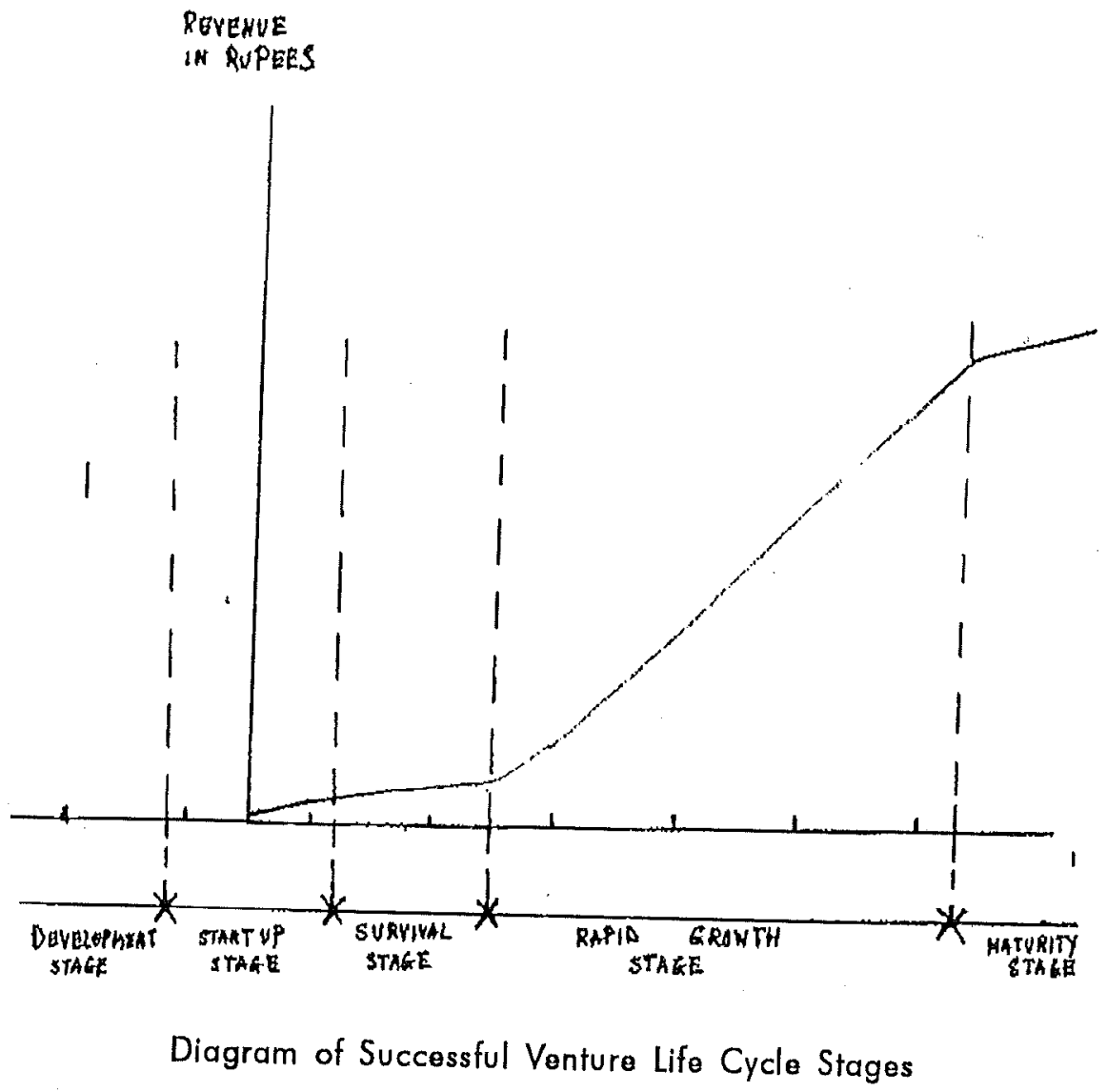

\section{Successful Venture Life Cycle Stages}

It is worth studying the business development of a successful venture and its relationship with marketing research required at various stages. The ultimate aim for any entrepreneur is economic growth resulting in profitability. To sustain this economic growth an appropriate marketing strategy with specific marketing research is essential. 


\section{Life Cycle Stages of the Successful Venture}

Successful ventures frequently follow a maturity progression known as a life cycle, shown in the diagram given. The venture life cycle begins with the development stage and progresses through various stages of revenue growth and concludes with a maturity stage. While venture life cycles also can be expressed in terms and of profit and or cash flows, it is standard practice to use revenues.

\section{Development Stage}

The first stage is the development stage which involves progressing from an idea to a possible business opportunity. Most new ventures begin with an idea for a potential product, service, or process. The feasibility of an idea is first put on trial during the development stage. The entrepreneur first discuss with his close circle of friends, relations and entrepreneurship professors for initial screening and deciding whether the idea can be pursued further. As a secondary step the reaction and interest level of trusted business professionals provides additional feedback. If these discussions are encouraging, the entrepreneur takes the next step of producing a prototype, delivering a trial service, or implementing a trial process?

The time to market is often a critical factor in whether a new idea is converted to a successful opportunity. At this stage marketing research should be aimed at only target markets. Potential customers should give their opinion on whether the idea conceived matches their desire, the possible design of the product which will satisfy their needs, their preference for the entrepreneur's product, whether the competitors have better attributes in their products, how much the customers are presently spending on similar products, how much they will spend on the entrepreneurs product?

\section{Startup Stage}

The second stage of a successful venture's life cycle is the startup stage, or time period when the venture is organized, developed, and an initial revenue model is put in place. In some instances, the process of acquiring necessary resources can take less than one year. For example, a business venture requiring little physical and intellectual capital and having simple production and delivery processes might progress from the initial idea to actual startup in one year or less. Revenue generation typically begins at the zero point of the axis of the diagram. At this point 'zero' the venture begins to operate and sell its first products or services. 
At this stage the marketing research has already indicated the product launching requirements. Research will answer questions as the correct time of product launch, decision about soft launch, the target markets aimed, the channel of distribution decision, the product logistics decision, pricing decision, advertising decision and so forth. At this stage the marketing strategy should be at its aggressive best, as the first sales activities just start emerging after the incubation period of development.

\section{Survival Stage}

During the survival stage, revenues start to grow and revenue cash flows begin to pay for some of the expense cash flows. At this stage, operating cash uses typically exceed operating cash sources and the difference is covered by borrowing or by allowing others to invest in the venture. Importantly, however, tenders and investors will only provide financing when they expect the venture's cash flows from operations to be large enough to repay the investment and provide for additional returns. Consequently, ventures in the survival stage begin to have serious concerns about the financial impression they leave on outsiders. Formal financial statements and planning begin to have useful external purposes.

Marketing thrust is essential over the entire channel of distribution. Sales promotions at retail outlets or even in direct marketing are encouraged. Market research should be aimed to find out the total market share, building up the brand equity, sales performance, sales territory analysis, deciding on practical sales targets, competitive analysis and so on.

\section{Rapid Growth Stage}

The fourth stage of a successful venture's life cycle is the rapid growth stage where revenues and cash inflow grow very rapidly cash flows from operations grow much more quickly than do cash outflows, resulting in a large appreciation in the venture's value. Ventures that successfully pass through the survival stage are often the recipients of substantial market share gains taken form less successful firms struggling in their own survival stage. Continued industry revenue growth and increased market share combine to propel the venture towards its lucrative financial future. During this period in a successful venture's life, value increases rapidly as revenue increases more rapidly than expenses. The successful venture reaps the benefits of economics of scale in production and distribution. 
The entrepreneur considers the rapid growth stage the most lucrative stage. The marketing efforts are all geared in sales maximization and turnover expansion. At this stage an entrepreneur needs to continually review the methods employed for sales and distribution in relation to the market research that has been conducted. This is performed by sales research.

\section{Sales Research}

Matching the correct customer profile with sales priorities is a major goal in sales research. The following is a list of effective questions to be answered by this research;

1) Do sales people call on their most qualified prospects on a proper priority and time - allocation basis?

2) Does the sales force contact decision markers?

3) Are territories aligned according to sales potential and sales people's abilities?

4) Whether the sales calls are coordinated with other selling efforts, such as trade publication advertising, trade shows, and direct mail?

5) Are the sales people asking the right questions on sales calls?

6) Do sales reports contain appropriate information? Are the sales force understanding potential customer's needs?

7) Do the growth or decline of a customer's or a prospect's business affect the company's own sales? If so, to what extend?

\section{Maturity Stage}

The fifth and the final stage in a successful venture's life cycle is the maturity Stage where the growth of revenue and cash flow continues but at much slower rates than in the rapid growth stage. The value continues to increase modestly, but most venture value has already been created and recognized during the rapid growth stage. The maturity stage often coincides with decisions by the Entrepreneur and other investors to exit the venture through a sale or merger. It is up to the entrepreneur to decide whether to continue a steady business or sell it off at a good price, to invest in another new venture.

Marketing research applied at the maturity stage would be centered on investigating on untapped markets or segments, finding out need and demand 
of repositioning, customers demand for change in product attributes, deciding on price culting and discounts and so on. The overall marketing strategy will be to clear old stock, plan discount clearance sale and plan stock clearing sales promotion (buy one take two, economy pack of a number of products, discount sales, free gifts, coupons and so forth).

Repositioning of consumer products are common as this infuses new life to the product. Marketers in this case should do new product designing (with minor alterations to the existing product), new target marketing, product repositioning, perceptual mapping, and finally re-launching the altered product.

\section{Conclusion}

Thus we may conclude by stating market research is a fundamental responsibility for planning a new venture, and having good information during the pre - startup planning stage, cannot be overemphasized. Entrepreneurs must establish how they will complete in clearly defined markets. The major implication of doing market research is to establish that demand exists for a product or service, and part of this task is to articulate the assumptions related to demand such as pricing, quality, distribution, and the distinct competency of a venture. A thorough competitive analysis will result in an understanding of the venture, its strengths and weaknesses, and both the threats it may face and opportunities that may arise. As long as entrepreneurs are in business, market research is a pervasive and important responsibility.

\section{Bibliography}

- Alfred M. Petham, "Market Orientation and other potential influences on performance in Small and Medium-Sized Manufacturing Firms," Journal of Small Business Management (January 2000) 48- 67.

- Stephen W. Mc Daniel and A. Parasuraman, "Practical Guidelines for Small Business Marketing Research," Journal of Small Business Management (January 1986); 1 - 7.

- Alan R. Andreasen, "Cost Conscious Marketing Research," Harvard Business Review (July / August 1983)' $74-75$.

- Hisrich, Peters, "Entrepreneurship," (Inwin / Mc Graw - Hill, 1998. USA)IV ED. 
- Donald. F. Kuratko and Richard M. Hodgetts. "Entrepreneurship - Theory, Process, Practice" (Thomson South Western 2004) USA. VI ED.

- J. Chris Leach and Ronald W. Melicher "Entrepreneurial Finance" (Thomson South Western 2003. USA)

- David H. Holt "Entrepreneurship. New Venture Creation" (Practice Hall of India 2003 New Delhi). 